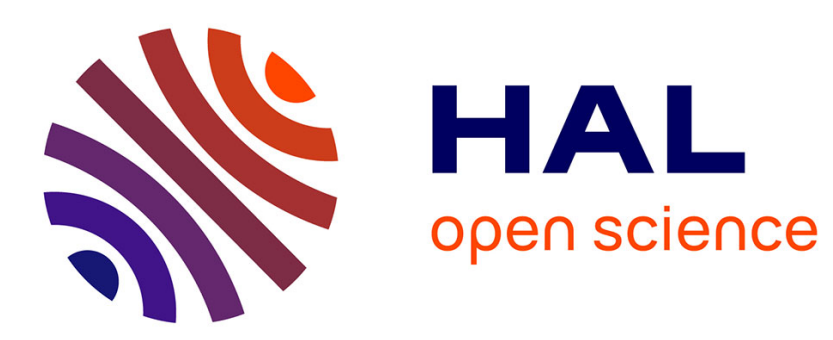

\title{
Application of age-momentum correlation measurements for studies of the formation of positronium and its reactions in liquids
}

\author{
A. Uedono, R. Suzuki, S. Tanigawa
}

\section{- To cite this version:}

A. Uedono, R. Suzuki, S. Tanigawa. Application of age-momentum correlation measurements for studies of the formation of positronium and its reactions in liquids. Journal de Physique IV Proceedings, 1993, 03 (C4), pp.C4-143-C4-145. 10.1051/jp4:1993419 . jpa-00251462

HAL Id: jpa-00251462

https://hal.science/jpa-00251462

Submitted on 1 Jan 1993

HAL is a multi-disciplinary open access archive for the deposit and dissemination of scientific research documents, whether they are published or not. The documents may come from teaching and research institutions in France or abroad, or from public or private research centers.
L'archive ouverte pluridisciplinaire HAL, est destinée au dépôt et à la diffusion de documents scientifiques de niveau recherche, publiés ou non, émanant des établissements d'enseignement et de recherche français ou étrangers, des laboratoires publics ou privés. 


\title{
Application of age-momentum correlation measurements for studies of the formation of positronium and its reactions in liquids
}

\author{
A. UEDONO, R. SUZUKI ${ }^{(1)}$ and S. TANIGAWA \\ Institute of Materials Science, University of Tsukuba, Ibaraki 305, Japan
}

\begin{abstract}
The age-momentum correlation measurements were applied to the study of annihilation characteristics of positrons and positronium (Ps) in benzene, carbontetrachloride and those mixtures. The observed lifetime spectra and Doppler broadening profiles were decomposed into two-components. The inhibition of the Ps formation by carbontetrachloride was observed in a momentum dependence of the lifetime and in a time dependence of the $S$ parameter.
\end{abstract}

\section{Introduction}

It is well known that positronium (Ps) is formed when energetic positrons are injected into liquids. The formation of Ps is usually detected by the long-lived component in lifetime spectra of positrons. Analysis of the lifetime spectra enables us to obtain information on chemical reactions between Ps and molecules. However, since the lifetime spectrum for liquids is the superposition of various annihilation modes, the decomposition of the short-lived components is difficult. Carbontetrachloride is known to be an efficient inhibitor of the Ps formation, and the inhibition of the Ps formation was studied by the analysis of the long-lived component in lifetime spectra. ${ }^{1-3}$ It has been suggested that the age-momentum correlation measurement is a powerful tool to separate some coexistent annihilation modes. ${ }^{4}$ Thus, in the present paper, we applied the age-momentum correlation measurements in order to study annihilation characteristics of positrons and Ps in benzene, carbontetrachloride and their mixtures.

\section{Experimental}

The specimens used in the present experiment were benzene, carbontetrachloride and their mixtures. These specimens were degassed and transferred into cylindrical glass vessels. The age-momentum correlation spectra were measured by the system constructed at the University of Tsukuba. 4 The obtained lifetime spectra were decomposed into two components by using RESOLUTION 5 . The Doppler broadening profiles were characterized by the $S$ parameter, where the central region of the spectrum was defined from $\sim 510.5 \mathrm{keV}$ to $\sim 511.5 \mathrm{keV}$.

\section{Results and Discussion}

Figures 1 and 2 show the momentum dependence of the mean lifetime, $\tau_{M}$, and the time dependence of the $S$ parameter for benzene, carbontetrachloride and those mixtures, respectively. For carbontetrachloride, the momentum dependence of $\tau_{M}$ and the time dependence of $S$ were nearly flat. This means that positrons annihilate from only one state in carbontetrachloride. Since the obtained lifetime is shorter than that corresponding to the pick-off annihilation of ortho-Ps, it can be concluded that Ps is not formed in carbontetrachloride. For benzene and benzene-carbon tetrachloride solutions, the value of $\tau_{\mathrm{M}}$ at $|\Delta E|=2 \sim 4 \mathrm{keV}$ and that of $S$ at $t \approx 0$ ns were found to increase. Figures $3 \sim 6$ show the momentum dependence of the first lifetime, $\tau_{1}$, and that of the second component, $I_{2}$, for each specimen. Figure 7 shows the time dependence of the $S$ parameter corresponding to the short-lived component for these specimens, where the values denoted by $S_{\tau_{1}}, S_{\tau_{2}}, S_{\text {tot }}$ are the average values of $S$ for the short-lived 


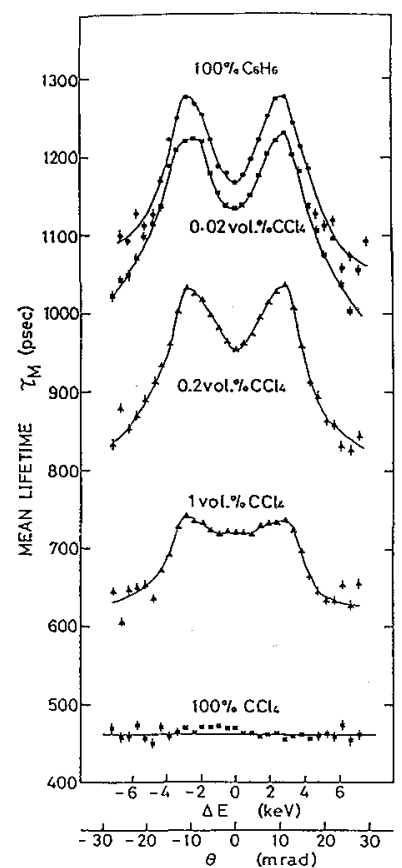

Fig. 1. The momentum Fig. 2. The time dependence of Fig. 3. The momentum dependence of $\tau_{M}$ for benzene carbontetrachloride solutions.

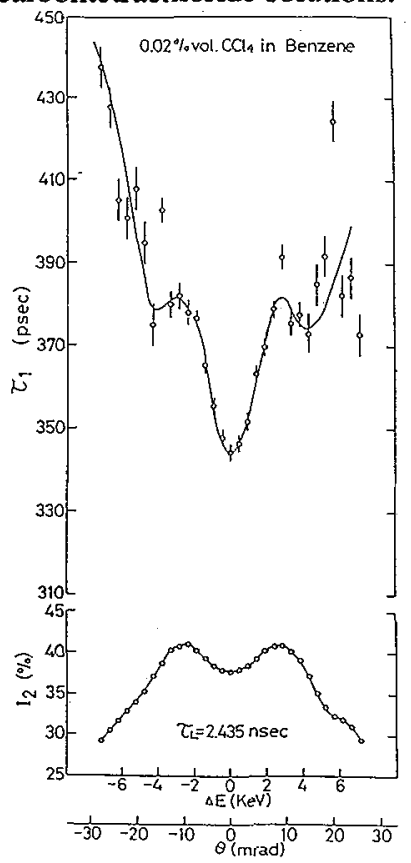

Fig. 4. The momentum Fig. 5. The momentum dependence of $\tau_{1}$ and of $I_{2}$ for dependence of $\tau_{1}$ and of $I_{2}$ for 0.02 vol. $\% \mathrm{CCl}_{4}$ in $\mathrm{C}_{6} \mathrm{H}_{6}$.
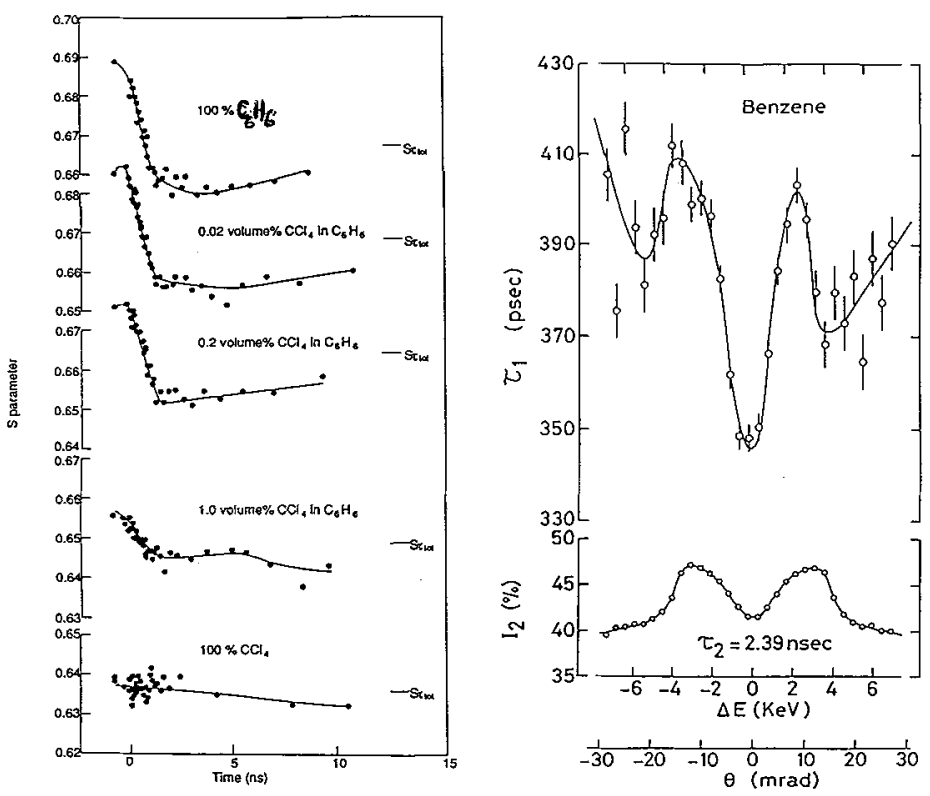

the $S$ parameter for benzene carbontetrachloride solutions.

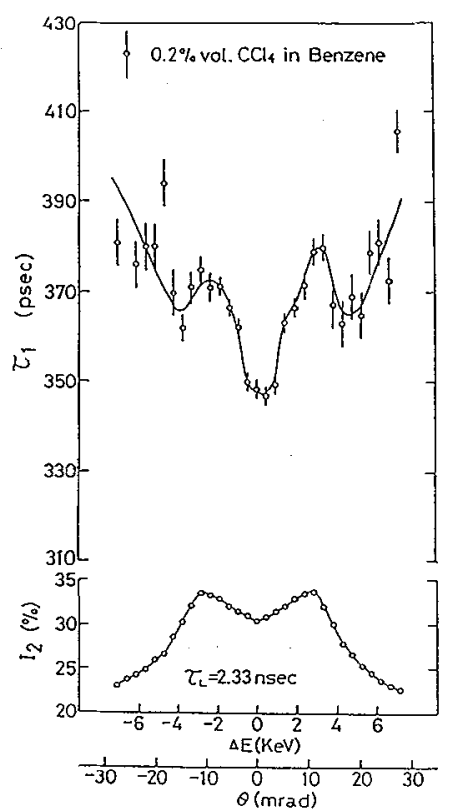

fetime of the short-lived component, $\tau_{1}$, and the long-lived component, $I_{2}$ for benzene.

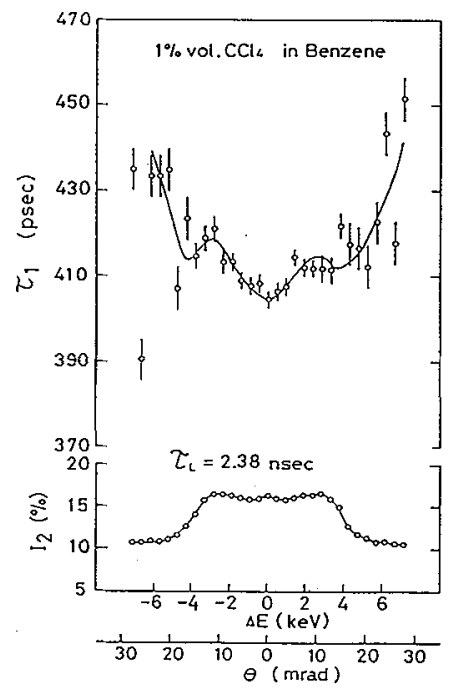

Fig. 6. The momentum dependence of $\tau_{1}$ and of $I_{2}$ for 1.0 vol. $\% \mathrm{CCl}_{4}$ in $\mathrm{C}_{6} \mathrm{H}_{6}$. 


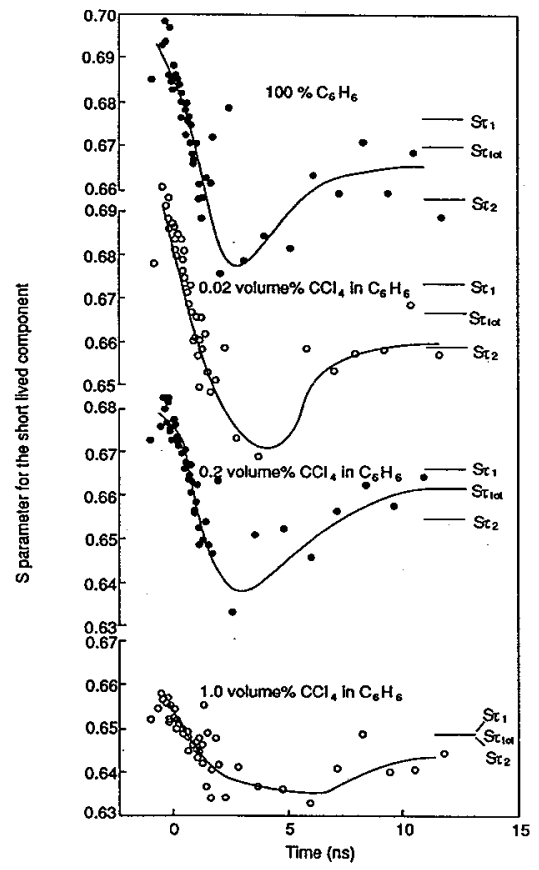

Fig. 7. The time dependence of the $S$ parameter corresponding to the short-lived component for benzene carbontetrachloride solutions.

between benzene and carbontetrachloride. carbontetrachloride causes a decrease in the dips of both $\tau_{1}$ and $I_{2}$ at $|\Delta E|=0 \mathrm{keV}$. This corresponds to the decrease in the intensity of the mode with the narrowest momentum distribution and the shortest lifetime, that is, the decrease in the intensity of self annihilation of para-Ps. The overall decrease of $I_{2}$ also corresponds to the decrease in the intensity of the pick-off annihilation of ortho-Ps. In Fig. 7, the value of $S$ at $t=0 \mathrm{~ns}$ was found to decrease with increasing the content of carbontetrachloride. This is also attributed to the inhibition of the Ps formation by carbontetrachloride. No drastic change in the $S-t$ plots and in $\tau_{1}-\Delta E$ plots due to the reaction between positrons and carbontetrachloride was observed.

\section{Conclusion}

We have presented the application of the age-momentum correlation measurement for the study of the formation of Ps and its reaction in benzene, carbontetrachloride and those mixtures. From the measurements, it was found that at least five annihilation modes coexisted for benzene and benzenecarbon tetrachloride solutions. The inhibition of the Ps formation by carbontetrachloride was successfully observed in the time dependence of $S$ corresponding to the short-lived component and the momentum dependence of $\tau_{1}$.

\section{References}

/1/ GOLDANSKII,V.I., V.P.Shantarovich and A.V.Shishkin, Dokl. Akad.Nauk USSR 230 (1976) 351.

12/ ITO,Y., Y.Miyake and Y.Tabata, Radiat. Phys. Chem. 19 (1982) 315.

13/ ITO,Y., Positron and Positronium Chemistry, edited by D.M.Schrader and Y.C.Jean (Elsevier, New York, 1988) p.120.

14/ KISHIMOTO,Y., S.Tanigawa, Int. Conf. of Positron Annihilation, edited by P.G.Coleman, S.C.Sharma and L.M.Diana (North-Holland, Amsterdam, 1982) p.815.

15/ KIRKEGAARD,P. and M.Eldrup, Computer Phys. Commun. 7 (1974) 410. 